ISSN 1112-9867

http://www.jfas.info

\title{
RELATIONSHIP BETWEEN BODY MASS INDEX, WAIST CIRCUMFERENCE, FAT MASS AND FAT PERCENTAGE AS A MEASUREMENT OF OBESITY AMONG UNIVERSITI PENDIDIKAN SULTAN IDRIS STUDENTS
}

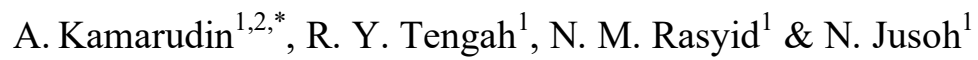 \\ ${ }^{1}$ Faculty of Sports Science and Coaching, Universiti Pendidikan Sultan Idris, Tg Malim, \\ Perak, Malaysia \\ ${ }^{2}$ Faculty of Sports Science and Recreation, Universiti Teknologi MARA, Arau, Perlis, \\ Malaysia
}

Published online: 10 November 2017

\begin{abstract}
The purpose of the study was to determine the prevalence of obesity based on the Body Mass Index (BMI), waist circumference, and fat mass and fat percentage and to examine the relationship between BMI, waist circumference, fat mass and fat percentage as the measurement of obesity among university students. The participants were 305 students from Univesiti Pendidikan Sultan Idris (UPSI) aged between 18-25 years old with males $(\mathrm{n}=101)$ and females ( $\mathrm{n}=204)$. Digital InBody Stadiometer was used to measure height. Body Composition Analyzer was used to determine body mass, fat percentage, fat mass and body mass index. Seca - SC100 tapes was used to measure waist circumference. The data was analysed using descriptive statistic to determine the prevalence of obesity and the Pearson correlation was used to determine the relationship between the variables being studied. Results showed that the prevalence of obesity based on BMI in male was 34.6. \% overweight and $12.9 \%$ obese and $31 \%$ was overweight and $12 \%$ obese among female participants.
\end{abstract}

Author Correspondence, e-mail: hazzur12@gmail.com

doi: http://dx.doi.org/10.4314/jfas.v9i6s.86 
The prevalence of obesity according to BMI was higher in men if compare to women. The results of waist circumference showed the greater number of females (71.6\%) being overweight compared to males $(64.3 \%)$. Overall, there was a strong, positive correlation between body mass index, waist circumference, fat mass and fat percentage in measuring obesity.

Keywords: Overweight, Obese, BMI, Waist circumference, and Fat mass

\section{INTRODUCTION}

The great changes in people's lifestyles have caused obesity, which is linked to urbanization and economic growth to become prevalent [33]. The prevalence of obesity is increasing in every country of the world [16]. It is estimated that more than 1.1 billion adults and 115 million children worldwide are overweight and obese [13]. The prevalence of obesity has reached epidemic level in Malaysia. According to the National Health and Morbidity Survey [18], 33.3\% and $27.2 \%$ of Malaysians above 18 years of age are overweight and obese respectively. Furthermore, the cost of obesity to the Malaysia health system exceeded RM20 billion in 2014, and this included costs associated with consequent metabolic disease, cardiac disease and surgical complications [15].

Body Mass Index (BMI) is widely used to measure obesity. However, the BMI is unable to differentiate between lean mass and fat mass, and hence, it is limited by differences in body adiposity for a given BMI across age, gender and ethnicity [11]. Obesity based on BMI, may actually underestimate obesity among Asians populations [19]. In addition, the BMI is only for screening process survey and does not consider fat mass distribution [23]. BMI is often used to assess risk of disease among adults [28]. Waist circumference a simple measure of fat contribution in body, has been observed to be a stronger predictor of obesity-related risk factors than BMI in adults $[3,7,14,22]$. Most literature suggested that waist circumference should come along with body mass index measurement to identified the risk of disease and there are a lot of studies using this two methods [5, 28, 29].

Body Mass Index prevalence needs supported by waist circumference where by for obesity predictor range were $104 \mathrm{~cm}$ for male and $88 \mathrm{~cm}$ for female [3] and overweight the score more than $80 \mathrm{~cm}$ and $94 \mathrm{~cm}$ approximately for female and male [5, 10, 17, 26]. A national 
survey among Malaysians university students showed obesity prevalence was significantly higher in the Malay women, compared to the Indians and Chinese [24]. Serious concerns arise, as obesity is a core risk factor for the development of several diet- related chronic diseases.

University students are a national asset for the future that will generate this country to in order to face urbanization and promote economic growth. These young people should have a healthy life and one of the indicator is their body condition. Peltzer (2014) reported that high prevalence of overweight and obesity from 22 universities. In Asia, the prevalence percentage of obesity were found that (Bangladesh: 20.8\% [27]; China: 2.9\%-14.3\% [25, 12] ; Malaysia: 20\%-30.1\% [2, 6]: Thailand: 31\% [1]: Pakistan: 13\%-52.6\% [4, 9] and India: 11\%-37.5\% [21]; The rising prevalence of overweight and obesity in universities were $49 \%$ because of inactive lifestyle [8] and increase consumption of high calorie foods [23] that not a healthy food [27].

Thus the present study aimed to determine the prevalence of obesity based on the BMI, waist circumference, fat mass and fat percentage. This study also aimed to investigate the relationship between BMI, waist circumference, fat mass and fat percentage as a measurement of obesity among the students of Universiti Pendidikan Sultan Idris (UPSI).

\section{METHODS}

\subsection{Participants}

This study was conducted at Universiti Pendidikan Sultan Idris (UPSI). A total of 305 students age between 18 to 25 years old comprised of 101 males and 204 females were voluntarily participated in the study. The participants were given verbal and written instructions outlining the protocol and written informed consent was obtained before the measurement of their body composition. The study was conducted in accordance to the Declaration of Helsinki.

\subsection{Procedure}

Height was measured in 0.125 -inch $(0.32 \mathrm{~cm})$ intervals using a stadiometer digital InBody BSM-370 Stadiometer (Seoul, Korea). Body mass, fat percentage, fat mass and body mass 
index has been assessed using Body Composition Analyzer (Inbody 3.0®, Biospace Co Ltd, Seoul, Korea). $\quad$ BMI were categorized as underweight $\leq 18.5 \mathrm{~kg} / \mathrm{m}^{2}$, overweight $25.0-29.9$ $\mathrm{kg} / \mathrm{m}^{2}$, and obese if BMI $\geq 30.0 \mathrm{~kg} / \mathrm{m}^{2}$ [32]. Waist circumference was measured on the skin around the abdomen at the level of the umbilicus with tape measurement Seca- SC100 (Hamburg, Germany). Waist circumference were categories as normal $\leq 93.5 \mathrm{~cm}$, overweight $94-101.9 \mathrm{~cm}$ and obese $\geq 102 \mathrm{~cm}$ for male and normal $<79 \mathrm{~cm}$, overweight $80-87.9 \mathrm{~cm}$ and obesity $88.0 \mathrm{~cm}$ for female [31].

\subsection{Statistical analysis}

Data analysis was conducted by using Statistical Package for Social Sciences version 20 (SPSS Inc., Chicago, IL, USA). Descriptive statistic was used to analyze the demographic and prevalence of obesity. The descriptive data were reported in mean, standard deviation, frequency and percentage. The relationship between anthropometric measures was examined using Pearson's correlation analysis. $P$ value $<0.05$ was set as significant value.

\section{RESULTS}

The basic characteristics of the participants are shown in Table 1. The participants comprised of 33.1\% ( $(\mathrm{n}=101)$ males and $66.9 \%(\mathrm{n}=204)$ females. The mean ages for male and female participants were $22.4 \pm 1.1$ and $22.31 \pm 1.3$ years old respectively. The frequency of exercise showed that most participants exercise either once or twice per week.

Table1. The demographic characteristic of the participants between genders. Values are

\begin{tabular}{lcc}
\multicolumn{3}{c}{ express as $\mathrm{M} \pm \mathrm{SD}}$. \\
\hline Variables & Males $(\mathrm{n}=101)$ & Female $(\mathrm{n}=204)$ \\
\hline Age (years) & $22.4 \pm 1.1$ & $22.31 \pm 1.3$ \\
Height $(\mathrm{cm})$ & $168.15 \pm 6.6$ & $156.78 \pm 5.1$ \\
Weight $(\mathrm{kg})$ & $71.34 \pm 14.0$ & $62.02 \pm 12.6$ \\
Frequency of exercise (day per week) & $1.29 \pm 0.9$ & $1.10 \pm 0.9$ \\
\hline
\end{tabular}




\subsection{Prevalence of obesity based on Body Mass Index (BMI).}

The prevalence of obesity according to BMI was higher in men compared to females. Table 2 showed $1.00 \%$ of female were underweight, $56 \%$ was normal, $31 \%$ was overweight and $12 \%$ was obese. While male participants showed $52.2 \%$ normal, $34.6 \%$ overweight and $12.9 \%$ was obese.

Table 2. Prevalence of obesity based on Body Mass Index (BMI) in male and female participants $(\mathrm{n}=305)$. Values are express as frequency and percentage $(\%)$.

\begin{tabular}{lccccc}
\hline \multicolumn{5}{c}{ BMI $\left(\mathrm{kg} / \mathrm{m}^{2}\right)$} \\
\hline \multirow{2}{*}{ Gender } & $\mathrm{N}$ & Underweight & Normal & Overweight & Obese \\
& & $<18.5$ & $18.5-24.9$ & $25.0-29.9$ & $\geq 30.0$ \\
\hline Male & 101 & - & $53(52.5 \%)$ & $35(34.6 \%)$ & $13(12.9 \%)$ \\
Female & 204 & $3(1 \%)$ & $115(56 \%)$ & $63(31 \%)$ & $23(12 \%)$ \\
\hline
\end{tabular}

\subsection{Prevalence of obesity based on waist circumference (cm).}

Table 3 showed the frequency and percentage waist circumference for male and female participants. The prevalence of overweight based on waist circumference was greater in females $(71.6 \%)$ compared to males $(64.3 \%)$. Likewise, there was a higher percentage of obesity observed in females (28.4\%) than in males $(12.9 \%)$.

Table 3. Prevalence of obesity based on waist circumference $(\mathrm{cm})$ in male and female participants $(n=305)$. Values are express as frequency and percentage $(\%)$.

\begin{tabular}{lccc}
\hline \multicolumn{3}{c}{ Waist Circumference $(\mathrm{cm})$} \\
\hline \multirow{2}{*}{ Gender } & Normal & Overweight & Obese \\
& $<93.9$ & $94-101.9$ & $>102$ \\
\hline Male (101) & $21(20.8 \%)$ & $65(64.3 \%)$ & $13(12.9 \%)$ \\
\hline \multirow{2}{*}{ Female (204) } & Normal & Overweight & Obese \\
& $<79.9$ & $80-87.9$ & $>88$ \\
\hline & - & $146(71.6 \%)$ & $58(28.4 \%)$ \\
\hline
\end{tabular}




\subsection{Correlation between BMI, waist circumference, fat mass and fat percentage.}

Table 4 showed the Pearson's correlation coefficients of body mass index, waist circumference, fat mass and fat percentage among male participants. There was a positive and significant correlation between body mass index and waist circumference $[r=0.732, n=101, p<0.000]$, body mass index and fat mass $[\mathrm{r}=0.725, \mathrm{n}=101, \mathrm{p}<0.000]$, body mass index and fat percentage $[r=0.686, n=101, p<0.000]$ and fat mass and percentage fat $[r=0.523, n=101$, $\mathrm{p}, 0.000]$. Overall, there was a strong, positive correlation between body mass index, waist circumference, fat mass and fat percentage to estimate obesity. Increases in fat mass and fat percentage were correlated with increases in obesity.

Table 4. Correlation between BMI, waist circumference, fat mass and fat percentage among male participant $(\mathrm{n}=101)$.

\begin{tabular}{lcccc}
\hline \multicolumn{1}{c}{ Variable } & BMI & $\begin{array}{c}\text { Waist } \\
\text { Circumference }\end{array}$ & Fat Mass & $\begin{array}{c}\text { Fat } \\
\text { Percentage }\end{array}$ \\
\hline BMI $\left(\mathrm{kg} / \mathrm{m}^{2}\right)$ & 1.000 & $0.732^{* *}$ & $0.725^{* *}$ & $0.686^{* *}$ \\
Waist circumference & $0.732^{* *}$ & 1.000 & $0.538^{* *}$ & $0.461^{* *}$ \\
$(\mathrm{~cm})$ & & & & $0.523^{* *}$ \\
Fat Mass & $0.725^{* *}$ & $0.538^{* *}$ & 1.000 & 1.000 \\
Fat percentage $(\%)$ & $0.686^{* *}$ & $0.461^{* *}$ & $0.523^{* *}$ & \\
\hline
\end{tabular}

** Correlation is significant at the 0.01 level (2 -tailed)

Table 5 shows the Pearson's correlation coefficients of body mass index, waist circumference, fat mass and fat percentage among female participants. There was a positive and significant correlation between body mass index and waist circumference $[r=0.683, n=204, p<0.001]$, body mass index and fat mass $[\mathrm{r}=0.826, \mathrm{n}=204, \mathrm{p}<0.000$, body mass index and percentage fat $[\mathrm{r}=0.700, \mathrm{n}=204, \mathrm{p}<0.001]$ and fat mass and percentage fat $[\mathrm{r}=0.671, \mathrm{n}=204, \mathrm{p}<$ 0.001]. The result indicates all four indicators were significant and the high relationship was between BMI and Fat Mass. Overall, there was a strong, positive correlation between body 
mass index, waist circumference, fat mass and fat percentage to estimate obesity. Increases in fat mass and fat percentage were correlated with increases in obesity for female participants.

Table 5. Correlation between BMI, waist circumference, fat mass and fat percentage among female participants $(n=204)$.

\begin{tabular}{|c|c|c|c|c|}
\hline Variable & BMI & $\begin{array}{l}\text { Waist } \\
\text { Circumference }\end{array}$ & Fat Mass & $\begin{array}{c}\text { Fat } \\
\text { Percentage }\end{array}$ \\
\hline BMI $\left(\mathrm{kg} / \mathrm{m}^{2}\right)$ & 1.000 & $0.683 * *$ & $0.826^{* *}$ & $0.700 * *$ \\
\hline $\begin{array}{l}\text { Waist circumference } \\
(\mathrm{cm})\end{array}$ & $0.683 * *$ & 1.000 & $0.538 * *$ & $0.458 * *$ \\
\hline Fat Mass & $0.826 * *$ & $0.538 * *$ & 1.000 & $0.671 * *$ \\
\hline Fat percentage $(\%)$ & $0.700 * *$ & $0.458 * *$ & $0.671 * *$ & 1.000 \\
\hline
\end{tabular}

** Correlation is significant at the 0.01 level (2 -tailed)

\section{DISCUSSION}

The goal of this study was to evaluate the relationship between body mass index, waist circumference, fat percentage and fat mass to estimate obesity among Universiti Pendidikan Sultan Idris (UPSI) students. Results showed the prevalence of obesity according to BMI was higher in men compare to women. Overall, there was a strong positive correlation between body mass index, waist circumference, fat mass and fat percentage to estimate obesity. Therefore the outcome of this study strongly showed that increases in body composition were correlated with increases in obesity.

The estimation for health screening base on BMI can underestimated the risk of disease (Vargas, 2008). Our results were in agreement with a number of studies mainly from Asia (Jingya, 2013; Gopalakrishnan, 2012; Banwell, 2009) which found that female population was associated with overweight and obesity. We speculated that in our study, the less frequency of exercise was probably one of the factors that may influence the high prevalence on overweight and obesity among UPSI students. 
Determining BMI does not require complex equipment and it is easy to calculate. However, in this study the highlighted limitation in its use, as a measure of adiposity is importance. In the present study the correlation coefficients between BMI and fat mass shows high correlation among the participants which was supported by previous studies (Peltzer et al., 2014; Haidar et al., 2012; Irving et al., 2009). The strong correlation between BMI and fat mass $(\mathrm{r}=0.683)$ indicated that the usage of waist circumference is useful to be used with BMI to estimate the prevalence of obesity for both genders. Indeed (Peltzer, 2014) suggested that BMI need supported by waist circumference to estimate the risk of disease predictor that is a useful replacement for the visceral adipose tissue area.

\section{CONCLUSIONS}

The present study has implications for the prevention of obesity in adult. As according to the National Health and Morbidity Survey (NHMS, 2011), 33.3\% and 27.2\% of Malaysians above 18 years of age are overweight and obese respectively. Universities need to address healthy environment and the need to promote healthy life styles as proposed by the WHO (2013) in the Global Strategy on Diet, Physical Activity and Health. Student themselves should be engaged in this process since they also need to be involved in promoting and living healthy lives. Therefore, appropriate measures to prevent further progression of the problem must be taken right at this stage otherwise obesity could emerge as a public health problem in adults.

\section{ACKNOWLEDGEMENT}

The authors acknowledge with thanks all members of Faculty of Sports Science and Coaching, UPSI. The authors acknowledge the men and women who participated in the study.

\section{REFERENCES}

[1] Banwell, C., Lim, L., Seubsman, S. A., Bain, C., Dixon, J., \& Sleigh, A. Body mass index and health-related behaviors in a national cohort of 87,134 Thai Open University students. Journal of Epidemiology Community Health. 2009, 63, 366-372. 
[2] Boo, N. Y., Chia, G. J., Wong, L. C., Chew, R. M., Chong, W., \& Loo, R. C. The prevalence of obesity among clinical students in a Malaysian medical school. Singapore Medical Journal. 2010, 51, 126 -132. 15.

[3] Brenner, D. R., Tepylo, K., Eny, K. M., Cahill, L. E., \& El-Sohemy, A. Comparison of body mass index and waist circumference as predictors of cardiometabolic health in a population of young Canadian adults. Diabetology \& Metabolic Syndrome. 2010, 2 (1), 2 - 28.

[4] Chaudhry, M. A., Ahmad, F., \& Ashraf, M. Z. Frequency of overweight and obesity in students of medical College Lahore. Annual report Institute Medicine Science. 2012, 8, $137-140$.

[5] Donnelley, J. E., Blair, S. N., Jakicic, J. M., Manore, M. M., Rankin, J. W., \& Smith, B. K. Appropriate physical activity intervention strategies for weight loss and prevention of weight regain for adults. Medicine and Science in Sports and Exercise, 2009, 41(2), 459-471.

[6] Gopalakrishnan, S., Ganeshkumar, P., Prakash, M. V., \& Amalraj, C.V. Prevalence of overweight and obesity among the medical students, Malaysia. Medicine Journal of Malaysia. 2012, 67, 442-444.

[7] Gubata, M. E., Urban, N., Cowan, D. N., \& Niebuhr, D. WA prospective study of physical fitness, obesity, and the subsequent risk of mental disorders among healthy young adults in army training. Journal of Psychosomatic Research, 2013, 75, 43-48.

[8] Haidar, Y.M., \& Cosman, B.C. Obesity epidemiology. Clinical Colon Rectal Surgery. $2011,24,205-210$

[9] Hingorjo, M. R., Syed, S., \& Qureshi, M. A. Overweight and obesity in students of a dental college of Karachi: Lifestyle influence and measurement by an appropriate anthropometric index. Journal Public Medicine Association. 2009, 59, 528-532.

[10]Irving, B., Davis, C. K., Brock, D. W., Weltman, Y., Swift, D., \& Weltman, A. The Body Composition Measurement. Medicine, Science Sports \& Exercise. 2009, 40(11), 1863-1872.

[11]Jackson, A. S., Stanforth, P. R., Gagnon, J., Rankinen, T., Leon, A. S. The effect of sex, age and race on estimating percentage fat mass from body mass index: The Heritage Family Study. International journal of obesity and related metabolic disorders: Journal of the International Association for the Study of Obesity . 2002, 26 (6), 789 - 796. 
[12]Jingya, B., Ye, H., Jing, W., Xi, H., \& Tao, H. Quantitative analysis and comparison of BMI among han, tibetan, and uygur university students in northwest china. Science World Journal. 2013, 4, 20- 33.

[13]Khor, G. Food availability and the rising obesity prevalence in Malaysia. E-Journal International Medical University. 2012, 6(1), 61-68.

[14]Mama, S. K., Diamond, P. M., Mccurdy, S. a, Evans, A. E., Mcneill, L. H., \& Lee, R. E. Individual, social and environmental correlates of physical activity in overweight and obese african american and hispanic women: A structural equation model analysis. Preventive Medicine Reports, 2015, 2, 57-64. doi: org/10.1016/j.pmedr.2015.01.001

[15]Ministry of Health (MOH, 2015). Annual Report Ministry of Health Malaysia 2015. http://doi.org/ISSN 1511-1512

[16]Mokhtari, T., Jamaluddin, R., \& Saad, H. A. Lifestyle and Psychological Factors Associated with Body Weight Status among University Students in Malaysia, 2015, 14 , 18 28.

[17]Molanorouzi, K., Khoo, S., \& Tony Morris. Motives for Adult Participation in Physical Activity: Type of Activity, Age, and Gender. BMC Public Health, 2015, 15, 66- 72.

[18]National Health and Morbidity Survey (NHMS 2011) Non-Communicable Diseases (Vol. III). Kuala Lumpur: Ministry of Health.

[19]Nwachukwu, D.C., Nwagha, U. I., Obikili, E. N., Ejezie, F. E., Okwuosa, C. N., Nweke, M. L., Ezeh, C. O. Assessment of body mass index and blood pressure among university students in, Enugu, South East, Nigeria. Niger Medical Journal. 2010, 19, 148-152.

[20]Peltzer, K., Pengpid, S., Alafia Samuels, T., Özcan, N. K., Mantilla, C., Rahamefy, O. H., \& Gasparishvili, A. Prevalence of overweight or obesity and its associated factors among university students from 22 countries. International Journal of Environmental Research and Public Health， 2014, 11(7), 7425-7441.

[21]Pengpid, S., \& Peltzer, K. Prevalence of overweight/obesity and central obesity and its associated factors among a sample of university students in India. Obese Res Clinical Practice. 2013, 12, 22-34 
[22]Pasco, J. A., Nicholson, G. C., Brennan, S. L., \& Kotowicz, M. A. Prevalence of obesity and the relationship between the body mass index and fat mass: Cross-sectional, population-based data. Plus One Journal, 2012, 7(1). doi: org/10.1371/journal.pone.0029580 [23]Popkin, B. M., Adair, L. S., \& Ng, S. W. Global nutrition transition and the pandemic of obesity in developing countries. Nutrition Review. 2012, 70, 3-21

[24]Rampal, L., Rampal, S., Khor, G.L., Azhar, M.Z., Shafie, O., Ramlee, R., Sirajoon, N.G. \& Krishna, J. A national study on the prevalence of obesity among 16,127 Malaysians. Asia Pacific Journal Clinical Nutrition; 2007, 16 (3): 561-566.

[25]Sakamaki, R., Toyama, K., Amamoto, R., Liu, C. J., \& Shinfuku, N. Nutritional knowledge, food habits and health attitude of Chinese university students - A cross sectional study. Nutrition Journal. 2005, 4, 4 - 14.

[26]Slentz, C., Aiken, L. B., Houmard, J., Bales, C. W., Johnson, J. L., Tanner, C. J., \& Kraus, W. E. Inactivity, exercise, and visceral fat. STRRIDE: a randomized, controlled study of exercise intensity and amount. Journal of Applied Physiology. 2005, 99, 1613-1618.

[27]Sultana, N., Nahar, S., Debnath, B .C., Rahman, M. Z., Naher, M .Q., \& Malik, S.U.F. Prevalence of obesity among the medical students in Sylhet. Jalalabad Medical Journal. 2011, $8,12-15$.

[28]Swaminathan, S., \& Schellenberg, E., G. Current Emotion Research in Music Psychology. Emotion Review, 2015, 7(2), 189-197.

[29]Thorstensson, C. a, Roos, E. M., Petersson, I. F., \& Ekdahl, C. Six-week high-intensity exercise program for middle-aged patients with knee osteoarthritis: a randomized controlled trial. BMC Musculoskeletal Disorders, 2005, 6, 27.

[30]Vargas, M., Becerra, F., \& Prieto, E. Anthropometric evaluation of university students in Bogotá, Colombia. Review health Publication. 2008, 10, 433-442.

[31] World Health Organization. Waist Circumference and Waist-Hip Ratio: Report of a WHO expert consultation. World Health Organization, 2008, 12, 8 - 11: doi.org/10.1038/ejcn. 2009. 139.

[32]World Health Organization. Global strategy on diet, physical activity and health. Geneva, Switzerland: World Health Organization.2013, 34-39. 
[33]Zhao, W., Zhai, Y., Hu, J., Wang, J., Yang, Z., Kong, L., \& Chen, C. Economic burden of obesity-related chronic diseases in Mainland China. Journal of Obesity Review, 2008, 9, 30-39.

\section{How to cite this article:}

Kamarudin A., Tengah R. Y., Rasyid N. Y. and Jusoh N. Relationship between Body Mass Index, Waist Circumference, Fat Mass and Fat Percentage as a Measurement of Obesity among Universiti Pendidikan Sultan Idris Students. J. Fundam. Appl. Sci., 2017, 9(6S), $1161-1172$. 